Jurnal Inkofar * Volume 1 No. 1, Juli 2018 * ISSN: 2615-3645 (Print) / 2581-2920 (Online)

Tersedia secara online di: http://www.politeknikmeta.ac.id/meta/ojs/

\title{
PENGARUH REWARD DAN PUNISHMENT TERHADAP KINERJA WELDER STUDI KASUS DI PROYEK PIPELINE SPREAD 4 LABUAN MARINGGAI - TANJUNG KARANG
}

\author{
Gunanto $^{1}$, Zulfa Fitri Ikatrinasari ${ }^{2}$ \\ ${ }^{1}$ Teknik Industri / Pasca Sarjana / Universitas Mercu Buana / gunanto.joshter@gmail,com \\ ${ }^{2}$ Teknik Industri / Dosen Pasca Sarjana / Universitas Mercu Buana / zulfafitri@gmail.com
}

\begin{abstract}
In the daily life of various activities to build the country or region. The project is a physical and non-physical activity that has a target to start and finish. One example of the main project is pipe installation. In the Welder position pipeline project is one of the key positions that determines many subsequent stages. To spur the welder performance, special strategies are needed so that the quality and time provided by the project owner can be guaranteed. Efforts to stimulate the performance of welders, one of which is to provide rewards and punisment. The information system used in the implementation of the Spread 4 Pipeline Project, Labuan Maringgai-Tanjung Karang, to find out the implications for the implementation of the project. In this study, the results of the performance, rewards and penalties of all welders were examined and then processed with SPSS software. The test results have a significant effect simultaneously on the variable reward (X1) and punishment (X2) on (Y) Welder Performance.
\end{abstract}

Keywords : Reward, Punishment, Welder performance.

\begin{abstract}
ABSTRAK
Dalam kehidupan sehari-hari berbagai kegiatan yang dilakukan untuk membangun suatu negara ataupun daerah. Proyek merupakan kegiatan fisik maupun non fisik yang mempunyai target mulai dan selesai. Salah satu contoh proyek fisik adalah proyek pemasangan pipeline. Dalam proyek pipeline posisi Welder merupakan salah satu posisi kunci yang menentukan banyak tahapan selanjutnya. Untuk memacu kinerja welder diperlukan strategi khusus agar bisa terjamin terpenuhinya kualitas dan waktu yang disediakan oleh pemilik proyek. Upaya memacu kinerja welder salah satunya adalah memberikan reward dan punisment. Penelitian ini bertujuan menganalisis penerapan sistem reward dan punishment terhadap kinerja Welder yang diterapkan dalam Proyek Pipeline Spread 4 Labuan Maringgai -Tanjung Karang untuk mengetahui implikasi terhadap pelaksaanaan proyek tersebut. Dalam penelitian ini diteliti hasil kinerja, reward dan punishment semua welder kemudian diolah dengan software SPSS. Hasil pengujian hipotesis menunjukkan ada pengaruh yang signifikan secara simultan dari variabel reward $\left(\mathrm{X}_{1}\right)$ dan punishment $\left(\mathrm{X}_{2}\right)$ terhadap $(\mathrm{Y})$ kinerja Welder.
\end{abstract}

Kata Kunci : Reward, Punishment, Kinerja welder.

\section{PENDAHULUAN}

Dalam kehidupan sehari-hari berbagai kegiatan yang dilakukan untuk membangun suatu negara ataupun daerah. Berbagai macam kegiatan fisik konstruksi maupun non konstruksi yang juga sering disebut proyek. Penyelesaian proyek memerlukan kinerja karyawan yang baik. Muda et.all (2014), faktor-faktor yang mempengaruhi kinerja karyawan antara lain tekanan pekerjaan, motivasi dan komunikasi. 
Pada proyek pipeline Labuan Maringai - Tanjung Karang mengalami keterlambatan penyelesaian. Dari main kontraktor membuat team task force untuk segera dapat menyelesaikan proyek tersebut Team task force yang terdiri dari berbagai keahlian, antara lain: pembantu (helper), skill worker (Fitter, Welder, Painter), pengawas dan Manajer lapangan, juga pendukung seperti quality control, PPIC, tukang gudang, Safetyman, Safety Officer dan lain sebagainya.

Hasil pengamatan pelaksanaan proyek pipeline yang menjadi sorotan mengenai hasil kerja team adalah penyelesaian pengelasan yang dilakukan oleh tukang las atau yang disebut Welder kurang memenuhi target. Welder merupakan salah satu kunci sukses proyek tersebut karena yang menyelesaikan sambungan pipa. Berdasarkan hasil pengamatan tersebut maka manager proyek menerapkan reward dan punishment di Spread 4 untuk meningkatkan kinerja Welder.

Pada penelitian sebelumnya diteliti pengaruh reward dan punishment terhadap kinerja hotel di Minahasa Selatan, namun tidak terdapat pengaruh yang signifikan (Suak, Adolfina, \& Uhing, 2017). Penelitian lain di PT Witel Jawa Timur diteliti reward dan punishment dihasilkan kesimpulan bahwa keduanya memberikan motivasi karyawan untuk dapat meningkatkan kinerjanya. (Suryadilaga, Almusadieq, \& Nurtjahyono, 2016). Dalam penelitian ini akan diteliti apakah ada pengaruh reward dan punishment di sebuah proyek konstruksi yang berbeda tipe dengan prinsip kerja di hotel, sejauh mana reward dan punishment mempunyai pengaruh terhadap kinerja welder di proyek Pipeline Spread 4 Labuan Maringgai - Tanjung Karang.

\section{STUDI PUSTAKA}

\subsection{Reward dan Punishment}

Penghargaan atau reward adalah balas jasa yang diberikan oleh perusahaan kepada karyawannya atas waktu, tenaga dan pikiran yang telah karyawan berikan kepada perusahaan (Sutrisno, 2009). Sedangkan tujuan utama perusahaan memberikan reward kepada karyawan adalah sebagai berikut : [1] Menarik orang yang memiliki kualifikasi. [2] Mempertahankan karyawan agar terus datang dan bekerja [3] Memotivasi karyawan untuk mencapai kinerja yang tinggi (Ivancevivivh, Matteson, \& Konopaske, 2006). Punishment adalah ancaman hukuman yang mempunyai tujuan untuk memelihara peraturan yang berlaku dan memberikan pelajaran kepada pelanggar Punishment merupakan kebalikan dari reward yaitu memberikan hukuman atas kinerja buruk yang dilakukan tenaga kerja, bisa berupa materiil maupun non materiil. (Mangkunegara \& Prabu, 2005).

Dalam Proyek Proyek Pipeline Spread 4 Labuan Maringgai - Tanjung Karang reward diberikan kepada Welder yang mencapai kualitas pengelasan yang lulus uji RT (radhiography test ) karena pengelasan di proyek ini harus 100\% lulus uji radhiography

Punishment adalah memberikan 2 kali lipat nilai reward jika pengelasan gagal di test radhigrapy dalam hal ini bisa dilakukan dengan pemotongan pemasukan Welder bisa dari reward atau gaji.

\subsection{Kinerja Welder}

Kinerja adalah hasil kerja yang dapat dicapai dalam suatu organisasi atau perusahaan oleh seseorang atau kelompok orang sesuai dengan wewenang dan tanggung jawabnya masingmasing untuk mencapai tujuan organisasi atau perusahaan bersangkutan secara legal tidak melanggar hukum, sesuai dengan moral maupun etika (Prawirosentono, 2008). Kinerja merupakan suatu fungsi kemampuan pekerja dalam menerima tujuan pekerjaan, tingkat pencapaian tujuan dan interaksi antara tujuan dan kemampuan pekerja menurut (Nawawi, 2006). Pendapat lain bahwa kinerja adalah pengabungan dari tiga faktor penting yaitu [1] faktor kemampuan, [2] faktor minat seseorang bekerja, [3] faktor kemampuan dan penerimaan atas penjelasan delegasi tugas dan peran serta tingkat motivasi seorang pekerja 
(Hasibuan, 2005). Semakin tinggi ketiga faktor di atas, maka semakin besarlah kinerja karyawan bersangkutan.

Welder menurut Kamus Bahasa Inggris Indonesia adalah tukang las. Tukang las orang yang mempunyai pekerjaan melakukan penyambungan besi atau logam lain dengan menggunakan metode las.

Jadi kinerja welder dalam penelitian ini adalah hasil pengelasan yang dicapai oleh welder (tukang las) selama periode tertentu yang di rata-ratakan dalam satu per bulan.

\subsection{Pengelasan}

Pengelasan adalah teknik penyambungan logam dengan cara mencairkan sebagian logam induk dan logam pengisi dengan atau tanpa logam penambah dan menghasilkan logam kontinyu (Siswanto, 2011). Logam pengisi disebut sebagai kawal las.

\subsection{Radiografi tes}

Radiografi adalah metode uji tidak merusak yang paling efektif karena penggunaan dan dapat diterima di industri. Radiografi untuk menguji sebagian besar material padat. Metode radiografi berdasarkan pengamatan perbedaan tingkat penyerapan dari suatu penyinaran radiasi pada suatu bahan/objek, atau dengan kata lain bayangan fotografik dihasilkan oleh lewatnya sinar gamma atau sinar x melalui benda uji ke film. Perubahan yang dihasilkan pada emulsi film dicuci unttuk menghasilkan radiographic transparency (radiograph).

\subsection{Pipeline}

Pipeline adalah serangkaian pipa lurus yang dilas bersama untuk jarak yang jauh, ditempatkan dibawah tanah atau diatas tanah, dan juga dibawah laut. Pipeline berfungsi sebagai jalur distribusi yang dalam penelitian ini adalah distribusi gas.

\subsection{Pengaruh Reward dan Punishment Terhadap Kinerja}

Penerapan reward bertujuan untuk dapat meningkatkan kinerja hasil kerja welder, karena mendapatkan imbalan yang lebih dari gaji yang diterima normal. Penerapan punishment bertujuan untuk memelihara iklim kerja yang terkendali agar karyawan melaksanakan tugas dan tanggung jawab dengan baik secara waktu dan kualitas bisa terkendali. Berdasarkan tinjauan teoritis dan tinjauan empiris, maka dalam penelitian ini disusun kerangkan konseptual seperti gambar berikut ini :

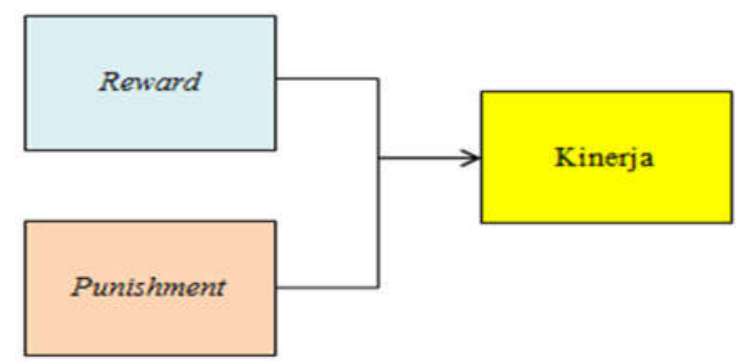

Gambar 1. Model konseptual

Berdasarkan konsep diatas, maka dalam penelitian ini dirumuskan hopotesis sebagai berikut:

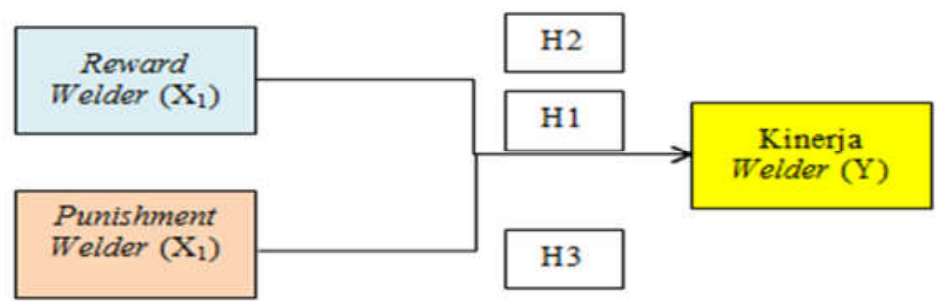

Gambar 2. Model Hipotesis 
Berdasarkan perumusan masalah, kajian teori dan model hipotesis, maka dalam penelitian ini dibuatlah hipotesis sebagai berikut ini :

$\mathrm{H} 1$ : Diduga terdapat pengaruh simultan yang signifikan dari $\left(\mathrm{X}_{1}\right)$ reward Welder dan $\left(\mathrm{X}_{2}\right)$ Punishment Welder terhadap (Y) Kinerja Welder.

$\mathrm{H} 2$ : Diduga terdapat pengaruh yang signifikan dari $\left(\mathrm{X}_{1}\right)$ reward Welder terhadap (Y) Kinerja Welder.

$\mathrm{H} 3$ : Diduga terdapat pengaruh yang signifikan dari $\left(\mathrm{X}_{2}\right)$ reward Welder terhadap (Y) Kinerja Welder.

\section{METODE PENELITIAN}

\subsection{Populasi}

Populasi dalam penelitian ini adalah semua welder yang ada di proyek Welder pada proyek Pipeline Spread 4 Labuan Maringgai - Tanjung Karang Lampung sejumlah 10 Orang. Data yang digunakan dalam penelitian ini berupa data sekunder yaitu laporan produksi pengelasan, reward pengelasan dan punishment pengelasan yang di buat oleh QC Proyek populasi welder . Data pengelasan dalam jumlah joint atau sambungan pipa.

Pendekatan yang digunakan dalam penelitian ini adalah kuantitatif mengacu pada teori yang ada mengenai reward, punishment, dan kinerja karyawan. Penggunaan program SPSS dalam penelitian ini digunakan untuk mengetahui sejauh mana pengaruh variabel bebas (reward dan punishment) mempengaruhi variabel terikat yaitu Kinerja.

\subsection{Metode Pengumpulan data}

Data yang dikumpulkan penelitian ini berasal dari data sekunder yaitu data laporan kinerja welder tentang jumlah produksi, reward dan punishment perbulan yang di rangkum sebagai berikut :

Tabel 1. Data Reward, Punishment dan Kinerja Welder

\begin{tabular}{|l|c|c|c|c|}
\hline \multirow{2}{*}{ NO } & \multirow{2}{*}{ Welder Name } & \multicolumn{2}{|c|}{ Variabel X } & Variabel Y \\
\cline { 3 - 5 } & & \multicolumn{2}{|c|}{ Independent } & dependent \\
\cline { 3 - 5 } & & $\mathrm{X}_{1}$ & $\mathrm{X}_{2}$ & Y \\
\cline { 3 - 5 } & & Reward & Punishment & Kinerja (Produktifitas) \\
\hline 1 & Welder 1 & 25,71 & 6,86 & 29,14 \\
\hline 2 & Welder 2 & 26,14 & 6,29 & 29,29 \\
\hline 3 & Welder 3 & 25,71 & 6,57 & 29,00 \\
\hline 4 & Welder 4 & 25,57 & 6,86 & 29,00 \\
\hline 5 & Welder 5 & 29,17 & 6,33 & 32,33 \\
\hline 6 & Welder 6 & 30,00 & 7,00 & 33,50 \\
\hline 7 & Welder 7 & 30,60 & 6,40 & 33,80 \\
\hline 8 & Welder 8 & 31,00 & 6,40 & 34,20 \\
\hline 9 & Welder 9 & 30,20 & 6,00 & 33,20 \\
\hline 10 & Welder 10 & 30,00 & 6,00 & 33,00 \\
\hline
\end{tabular}

Dari tabel di atas dijelaskan bahwa perolehan reward dan punishment Welder dalam jumlah joint yang kemudian di berikan dalam bentuk Rupiah, sebagai contoh perhitungan Welder 10 sebagai berikut :

Kinerja (Produktifitas)

Punishment

$$
\begin{aligned}
& =33 \text { Joint } \\
& =6 \text { Joint } \\
& =\text { Kinerja (Produktifitas) }- \text { Punishment } \\
& =33 \text { Joint }-6 \text { Joint } \\
& =30 \text { Joint } x \text { Rp 10.000,- (misal) } \\
& =\operatorname{Rp~} 257.100,- \text { (Misal) }
\end{aligned}
$$




\section{HASIL, ANALISA DATA DAN PEMBAHASAN}

Hasil uji asumsi klasik regresi linear (normalitas, Multikolinieritas, Heteroskedastisitas)

\subsection{Uji Validitas}

Gambar 3 dibawah ini menunjukkan gambar uji normalitas :

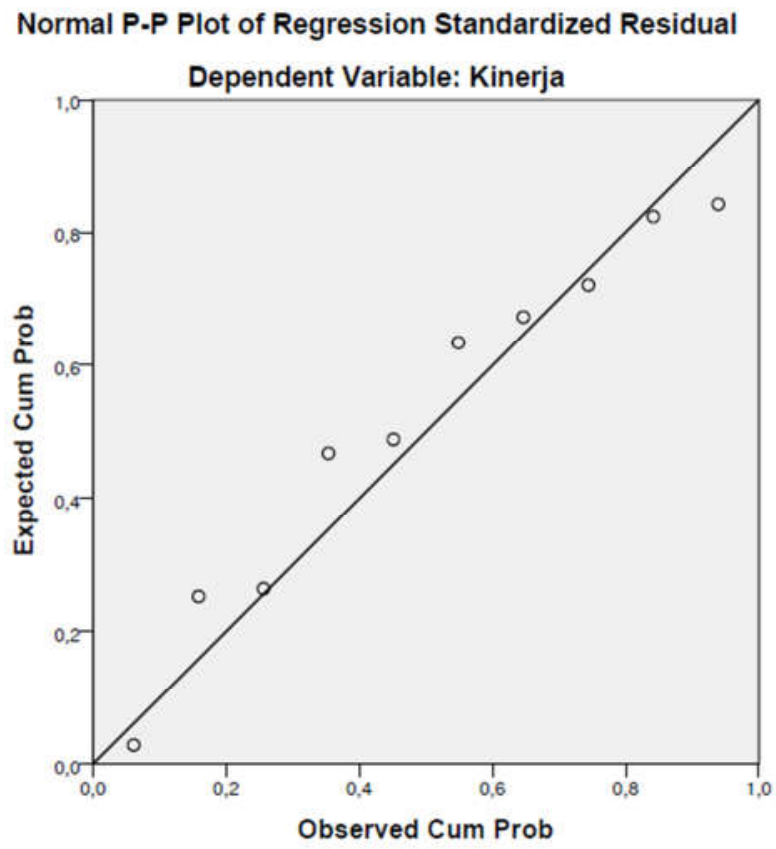

Gambar 3. Gambar uji Normalitas

Dari gambar 3 diatas terlihat titik-titik P-P Plot relatif mendekati garis lurus, sehingga dapat disimpulkan bahwa data residual terdistribusi normal, maka hasil ini sesuai dengan asumsi klasik regresi linear dengan pendekatan OLS.

Pada tabel 2 dibawah ini menunjukkan tabel hasil uji Multikolinieritas

Tabel 2. Uji Multikolinieritas

\begin{tabular}{|ll|r|c|}
\hline \multirow{2}{*}{ Model } & \multicolumn{2}{|c|}{ Collinearity Statistics } \\
\cline { 3 - 4 } & & Tolerance & \multicolumn{1}{c|}{ VIF } \\
\hline 1 & (Constant) & & \\
& Reward &, 805 & 1,242 \\
& Punishment &, 805 & 1,242 \\
\hline
\end{tabular}

Nilai VIF untuk variabel reward dan punishment sama - sama 1,242 sedangkan toleransinya 0,805 . Oleh karena nilai VIF kedua variabel tidak ada yang lebih besar dari 10 atau 5 maka dapat dikatakan tidak terjadi multikolinieritas pada kedua variabel bebas tersebut, maka sesuai dengan syarat asumsi klasik regresi linear dengan OLS.

Gambar 4 berikut ini menunjukkan gambar hasil uji Heteroskedastisitas : 


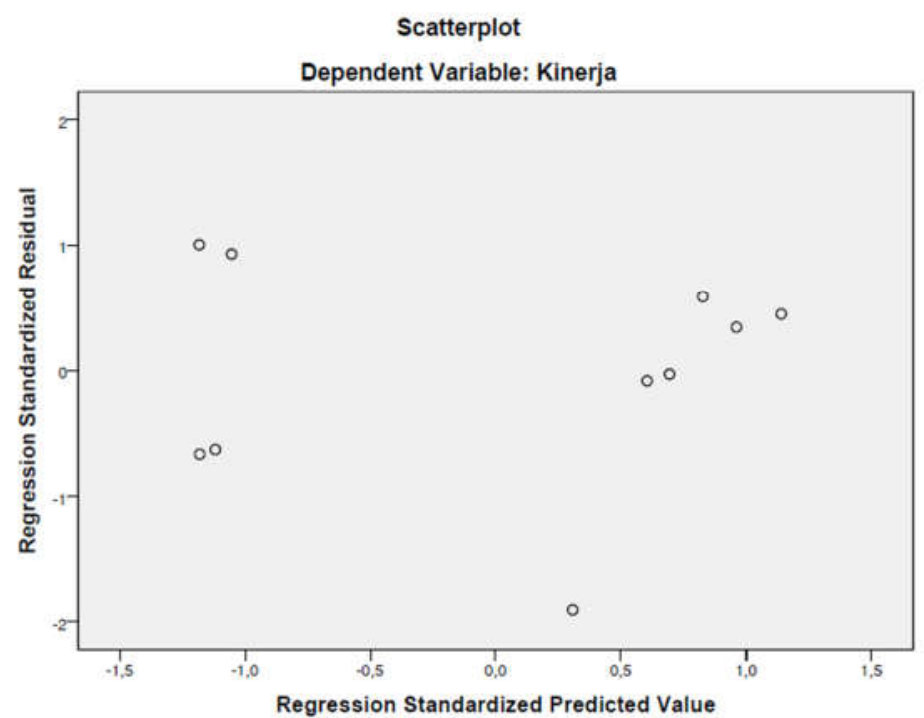

Gambar 4. Uji Heteroskedastisitas

Dari gambar diatas bisa terlihat bahwa sebaran titik tidak membentuk pola atau alur tertentu, sehingga bisa disimpulkan bahwa tidak terjadi heterodastisitas, maka bisa dikatakan homoskedastisitas.

\subsection{Hasil uji Analisis Regresi Linier Berganda}

Pada tabel 3 dibawah ini merupakan hasil uji regresi linear dengan sofware SPSS :

Tabel 3. Hasil uji regresi linear

\begin{tabular}{|c|c|c|c|c|c|c|}
\hline \multirow{2}{*}{\multicolumn{2}{|c|}{ Model }} & \multicolumn{2}{|c|}{ Unstandardized Coefficients } & \multirow{2}{*}{$\begin{array}{c}\begin{array}{c}\text { Standardized } \\
\text { Coefficients }\end{array} \\
\text { Beta } \\
\end{array}$} & \multirow[b]{2}{*}{$\mathrm{t}$} & \multirow[b]{2}{*}{ Sig. } \\
\hline & & $\mathrm{B}$ & Std. Error & & & \\
\hline \multirow[t]{3}{*}{1} & (Constant) & ,033 &, 027 & & 1,218 & ,263 \\
\hline & Reward & ,999 &, 000 & 1,032 & 2271,885 &, 000 \\
\hline & Punishment & ,498 &, 003 &, 078 & 171,105 &, 000 \\
\hline
\end{tabular}

Berdasarkan tabel diatas dapat dibuat persamaan sebagai berikut :

$$
Y=0,033+0,999 X_{1}+0,498 X_{2}
$$

$\mathrm{Y}$ adalah variabel terikat yang nilainya tergantung oleh variabel bebas $\left(\mathrm{X}_{1}\right.$ dan $\left.\mathrm{X}_{2}\right)$, dengan keterangan sebagai berikut :

$\mathrm{Y}$ (Variabel terikat) $=$ Kinerja Weder sedangkan

$\mathrm{X}_{1}($ Variabel bebas 1$)=$ Reward Weder

$\mathrm{X}_{2}($ Variabel bebas 2$)=$ Punishment Welder

Dari persamaan regresi linear berganda diatas dapat dijelaskan sebagai berikut :

1. Nilai konstanta sebesar 0,033 menunjukkan jika variabel Reward Welder $\left(\mathrm{X}_{1}\right)$ dan Punishment Welder $\left(\mathrm{X}_{2}\right)$ diabaikan atau diasumsikan 0 maka Kinerja Welder (Y) adalah sebesar 0,033, artinya sebelum atau tanpa adanya variabel Reward Welder $\left(\mathrm{X}_{1}\right)$ dan Punishment Welder $\left(\mathrm{X}_{2}\right)$ dalam perusahaan maka besarnya Kinerja Welder (Y) akan sebesar 0,033 .

2. Nilai koefisien variabel Reward Welder $\left(\mathrm{X}_{1}\right)$ sebesar 0,999 yang berarti bahwa kenaikan variabel Reward Welder $\left(\mathrm{X}_{1}\right)$ sebesar satu satuan, maka akan diikuti peningkatan Kinerja Welder (Y) sebesar 0,999 satuan dengan asumsi variabel bebas yang lainnya dianggap konstan. 
3. Nilai koefisien variabel Punishment Welder $\left(\mathrm{X}_{2}\right)$ sebesar 0,498 yang berarti bahwa kenaikan variabel Punishment Welder $\left(\mathrm{X}_{2}\right)$ sebesar satu satuan, maka akan diikuti peningkatan Kinerja Welder (Y) sebesar 0,498 satuan dengan asumsi variabel bebas yang lainnya dianggap konstan.

\subsection{Hasil Uji Hipotesis}

Pada tabel 4 dibawah ini merupakan hasil uji regresi linear dengan software SPSS :

Tabel 4. Hasil uji F ANOVA $^{\mathrm{a}}$

\begin{tabular}{|rl|r|r|r|r|r|}
\hline \multicolumn{1}{|c|}{} & \multicolumn{1}{|c|}{$\begin{array}{l}\text { Sum of } \\
\text { Sodel }\end{array}$} & Squares & df & Mean Square & \multicolumn{1}{c|}{ F } & Sig. \\
\hline 1 & Regression & 45,149 & 2 & 22,575 & 3009805,911 &, $000^{\mathrm{b}}$ \\
& Residual &, 000 & 7 &, 000 & & \\
& Total & 45,149 & 9 & & & \\
\hline
\end{tabular}

a. Dependent Variable: Kinerja

b. Predictors: (Constant), Punishment, Reward

Hipotesis yang digunakan dalam penelitian ini adalah sebagai berikut :

$\mathrm{HO}$ : Tidak terdapat pengaruh signifikan secara simultan dari variabel reward Welder $\left(\mathrm{X}_{1}\right)$ dan punishment Welder $\left(\mathrm{X}_{2}\right)$ terhadap kinerja $\operatorname{Welder}(\mathrm{Y})$

$\mathrm{Ha}$ : Terdapat pengaruh signifikan secara simultan dari variabel reward Welder $\left(\mathrm{X}_{1}\right)$ dan punishment Welder $\left(\mathrm{X}_{2}\right)$ terhadap kinerja Welder $(\mathrm{Y})$

Pada Tabel 4 menunjukkan nilai $F$ hitung sebesar 3009805,911 sedangkan $F$ tabel $(\alpha=0,05$; $\mathrm{db}$ regresi $=2: \mathrm{db}$ residual $=7$ ) adalah sebesar 4,74. Berdasarkan pengujian hipotesis model regresi secara simultan menggunakan uji $\mathrm{F}$ diketahui bahwa $\mathrm{F}$ hitung $>\mathrm{F}$ tabel $(3009805,911$ $>4,74)$ nilai sig. $F(0,000) \leq \alpha=0.05$. Hal ini berarti Ho ditolak dan Ha diterima sehingga dapat disimpulkan bahwa terdapat pengaruh signifikan secara simultan dari variabel reward Welder $\left(\mathrm{X}_{1}\right)$ dan punishment Welder $\left(\mathrm{X}_{2}\right)$ terhadap kinerja Welder $(\mathrm{Y})$.

\subsection{Hasil Uji Parsial (Uji t)}

Pada tabel 4 dibawah ini merupakan hasil uji $t$ dengan sofware SPSS :

Tabel 5. Hasil uji t

\begin{tabular}{|c|c|c|c|c|c|c|}
\hline \multirow{2}{*}{\multicolumn{2}{|c|}{ Model }} & \multicolumn{2}{|c|}{ Unstandardized Coefficients } & \multirow{2}{*}{$\begin{array}{c}\begin{array}{c}\text { Standardized } \\
\text { Coefficients }\end{array} \\
\text { Beta } \\
\end{array}$} & \multirow[b]{2}{*}{$t$} & \multirow[b]{2}{*}{ Sig. } \\
\hline & & B & Std. Error & & & \\
\hline \multirow[t]{3}{*}{1} & (Constant) & ,033 & ,027 & & 1,218 & ,263 \\
\hline & Reward & ,999 &, 000 & 1,032 & 2271,885 &, 000 \\
\hline & Punishment & ,498 & ,003 & ,078 & 171,105 &, 000 \\
\hline
\end{tabular}

Hipotesis yang digunakan dalam penelitian ini adalah sebagai berikut :

HO : Tidak terdapat pengaruh signifikan secara simultan dari variabel reward Welder $\left(\mathrm{X}_{1}\right)$ dan punishment Welder $\left(\mathrm{X}_{2}\right)$ terhadap kinerja Welder $(\mathrm{Y})$

$\mathrm{Ha}$ : Terdapat pengaruh signifikan secara simultan dari variabel reward Welder $\left(\mathrm{X}_{1}\right)$ dan punishment Welder $\left(\mathrm{X}_{2}\right)$ terhadap kinerja Welder $(\mathrm{Y})$ 
Jurnal Inkofar * Volume 1 No. 1, Juli 2018 * ISSN: 2615-3645 (Print) / 2581-2920 (Online)

Tersedia secara online di: http://www.politeknikmeta.ac.id/meta/ojs/

\subsection{Pengujian Hipotesis Variabel Reward Karyawan $\left(X_{1}\right)$ terhadap Kinerja Karyawan (Y)}

Pada Tabel 5 menunjukkan nilai $\mathrm{t}$ hitung sebesar 2271,885 sedangkan $\mathrm{t}$ tabel $(\alpha=0,05 ; \mathrm{db}$ regresi $=2: \mathrm{db}$ residual $=7$ ) adalah sebesar 2,365. Berdasrkan pengujian hipotesis model regresi secara simultan menggunakan uji t diketahui bahwa t-hitung $>$ t-tabel $(2271,885>$ $2,365)$ nilai sig. $F(0,000) \leq \alpha=0.05$. Hal ini berarti Ho ditolak dan Ha diterima sehingga dapat disimpulkan bahwa terdapat pengaruh signifikan secara simultan dari variabel reward Welder $\left(\mathrm{X}_{1}\right)$ dan punishment Welder $\left(\mathrm{X}_{2}\right)$ terhadap kinerja Welder $(\mathrm{Y})$

\subsection{Pengujian Hipotesis Variabel Punishment Karyawan $\left(X_{2}\right)$ terhadap Kinerja Karyawan (Y)}

Pada Tabel 5 menunjukkan nilai thitung sebesar 171,105 sedangkan $\mathrm{t}$ tabel $(\alpha=0,05 ; \mathrm{db}$ regresi $=2: \mathrm{db}$ residual $=7$ ) adalah sebesar 2,365. Berdasrkan pengujian hipotesis model regresi secara simultan menggunakan uji t diketahui bahwa t-hitung $>$ t-tabel $(171,105>$ $2,365)$ nilai sig. $\mathrm{F}(0,000) \leq \alpha=0.05$. Hal ini berarti Ho ditolak dan Ha diterima sehingga dapat disimpulkan bahwa terdapat pengaruh signifikan secara simultan dari variabel reward Welder $\left(\mathrm{X}_{1}\right)$ dan punishment Welder $\left(\mathrm{X}_{2}\right)$ terhadap kinerja Welder $(\mathrm{Y})$

\section{KESIMPULAN}

Berdasarkan hasil analisis data yang telah dilakukan dalam penelitian ini dapat ditarik kesimpulan sebagai bahwa reward dan punishment memberikan pengaruh terhadap kinerja welder di proyek Pipeline Spread 4 Labuan Maringgai - Tanjung Karang. Pada penelitian ini hanya diteliti kinerja welder berdasarkan reward dan punishment joint welding saja sehingga kedepan diperlukan penelitian-penelitian bagian yang lain yang mempengaruhi dan menunjang kinerja welder atau keberhasilan proyek.

\section{DAFTAR PUSTAKA}

Anonimos. (2002). Nondestrucive Testing Handbook Volume 4 Radhiographic Testing . USA: American Society for Nondestructive Testing Incorporated.

Hasibuan. (2005). Manajemen Sumber Daya Manusia. Jakarta: Bumi Aksara.

Ivancevivivh, Matteson, \& Konopaske. (2006). Perilaku dan Manajemen Operasi Jilid 1. Jakarta: Erlangga.

Mangkunegara, \& Prabu, A. (2005). Manajemen Sumber Daya untuk Perusahaan. Bandung: PT Remaja Rusdakarya.

Muda, I., Rafiki, A., \& Harahap, M. R. (2014, February 02). Factor Influencing Employees' Performance A Study on Islamic Banks in Indonesia. International Journal of Bussiness and Social Science Journal, 5(2), 73 - 80.

Nawawi. (2006). Evaluasi dan Manajemen Kinerja di Lingkungan Perusahaan dan Industri. Yogyakarta: UGM Press.

Prawirosentono. (2008). Manajemen Sumber Daya Manusia Kebijakan Kinerja Karyawan. Yogyakarta: BPFE.

Siswanto. (2011). Konsep Dasar Teknik Las (Teori dan Praktik). Jakarta: PT Prestasi Pustaka.

Suak, R., Adolfina, \& Uhing, Y. (2017). Pengaruh reward dan punishment terhadap kinerja karyawan Sutanraja Hotel Amurang. ISSN, 5(2), 1050-1059.

Suryadilaga, R. M., Almusadieq, M., \& Nurtjahyono, G. E. (2016, Oktober 01). Pengaruh Reward dan Punishment (studi pada Pt Telkom Indonesia Witel Jatim Selatan Malang). Jurnal Administrasi Bisnis, 39, 156 - 163.

Sutrisno. (2009). Manajemen Sumber Daya Manusia. Jakarta: Kencana. 